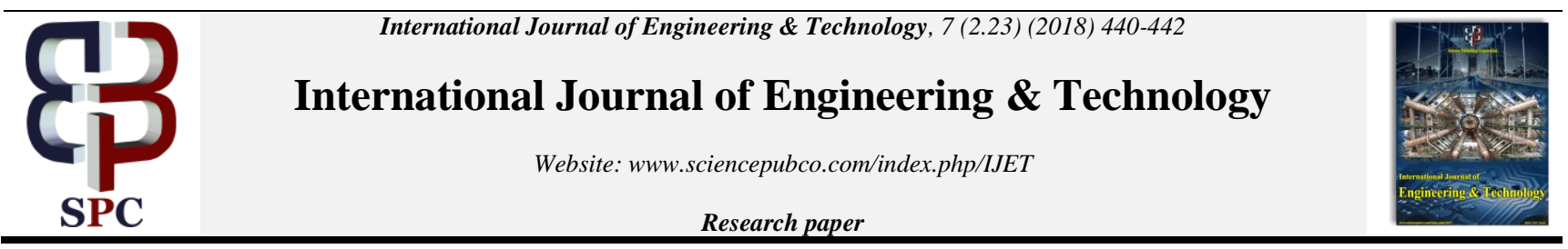

\title{
On the Issue of Neural Modeling of Some Dynamic Parameters of Earthquake
}

\author{
L.P. Haritonova ${ }^{1 *}$ \\ ${ }^{1}$ Associate Professor, Department Of Mathematics And Computer Technologies, Volgograd State Technical University, Volgograd, \\ Russia \\ *Corresponding Author E-Mail: Haritonova410@Yandex.Ru
}

\begin{abstract}
The author has attempted to refine the methods for modeling seismic effects. It is shown that applying the neural modeling and Artificial Neural Networks (ANN) are very prospective for analyzing such dynamic parameter earthquake foci as the moment magnitude. The further two input signals have been utilized: the power mode as well as the quantity of quakes. The author performed the analysis of regression for the predicted results and the target outputs. The article presents the equations of the regression (empirical dependences) for the outputs and target as well as the correlation factors for learning, assessment, checking, and the overall for the newly developed structure ANN for the moment magnitude. The use of the outcome obtained in this paper for the seismic designing and constructing structures and buildings will provide the conservation from possible consequences of earthquakes, reduce negative consequences for industry, the economy as a whole and human life.
\end{abstract}

Keywords: Correlation Coefficients; Dynamic Parameters of Earthquake; Moment Magnitude; Neural Network Modeling; Regression Analysis.

\section{Introduction}

A great number of people live and work in seismically dangerous regions. This fact puts extra requirements to guarantee the safety of structures to reduce the risks for the people located there. This issue is of special importance since we are observing the process of the seismic activation worldwide.

The mapping of seismic dangers is being done in acceleration in many lands apart from the Russian Federation where it is done in scores - the unit of the seismic activity scale.

Today, in order to design structures, it is needed to take into account not only soil acceleration, but also the velocity and duration of oscillations and their spectral distribution.

The values of earthquake vibrations in the epi-central area differ considerably from those long-offset ones. There is rarely an agreement as to the existing theoretical models in this issue [1].

It is very important to reveal the regularities in the formation of seismic vibrations as well as determination of correlation parameters of the environment, the earthquake focus, and the vibration properties.

One of the modern methods of seismic protection of buildings in the Russian Federation is to provide their seismic isolation, for instance in the cities of Sochi or Grozny [2].

The destruction of buildings and structures depends upon the spectral features of seismic motions. The most dangerous one is the resonance of soil column and the natural frequency of vibrations in a building.
The study of experimental data about the foci parameters of earthquakes will help create new theories of seismo-tectogenesis to reduce economic and human losses.

United Nations data show that in terms of the number of wounded or even killed in modern disasters, hydro-meteorological catastrophes are in the first place, geological (tsunami, floods, volcanic eruptions, earthquakes, etc.) take second place. Technogenic catastrophes are on the third place.

Recently, the pattern of growth in the number of man-made disasters with a simultaneous increase in natural disasters has been observed [3].

More than fifty percent of accidents are resulted from the following factors: the low degree of occupational safety and noneffective tracking of the environmental safety systems [4].

It is inadequate to investigate the effects of exclusively macroseismic activity on forecasting of the eventual seismic impact [5] for designing and constructing buildings.

The equations of connections (empirical dependences) obtained in paper [6] using the orthogonal regression method with the average interval values upon an energetic class for various dynamic parameters of earthquake sources such as the common logarithms of the earthquake moment, the dislocation radius (the circle on which a continuous stress relieving is observed), the magnitudes of the released stress (faulting), elastic shear strain in the focus vicinity, the value of dislocation (or the average rupture slip).

These dependences called in this paper the "long-term ones" were received from the information the analog seismic recording systems as a result of the generalizing of more then 500 pairs of characteristics of Crimean earthquakes in the outbreaks of the Crimean earthquakes from 1955 to 2007 years. 
Today, the various techniques of simulating the processes are very common [7-12]. The analysis of the publications did not allow to reveal the dependences of the moment magnitude generalizing the experimental results obtained (using including the neural simulation method).

It is of undeniable interest to know the correlation of seismic activity in scores and the parameters of considerable soil movements, the impact of the earthquake magnitude upon the soil acceleration amplitude values. There quite a number of non-linear phenomena insufficiently studied.

In this respect, it is important more than data approximation by the preselected formula but the derivation of exclusively empirical formulas [1].

\section{The Application of the Neural Modeling Method for Such Dynamic Earthquake Foci Parameters as a Moment Magnitude}

Based on the above-stated facts, this work suggests simulating some dynamic parameters applying the Neural Network modeling. Let us dwell on the moment magnitude $\boldsymbol{M}_{\boldsymbol{w}}$, which can be calculated using the formula of Hanks and Kanamori via earthquake moment (the power characteristic of a focus) [6].

The statistics [6] were used to analyze the dynamic parameters of earthquakes in the outbreaks of the 58 earthquakes in Crimea from 2007 to 2011 years.

These data are reconstructed from more than 300 amplitude spectra from digital seismic stations.

The network architecture has two nodes in input layer, which are the power class of the $K_{\Pi}$ as well as the quantity of quakes $\mathrm{N}$. Assuming the ANN network architecture as follows: 2-5-5-1.

The target data were $\boldsymbol{M}_{\boldsymbol{w}}$ - the moment magnitude. This study chose the Levenberg-Marquardt algorithm for network training. The hyperbolic tangent was applied in the capacity of the transfer function. MSE was utilized by way of the performance function.

\section{Results and Discussions}

The geometry of a structure ANN for the moment magnitude and some of the utilized algorithms have been presented in the first figure. Some outcome is shown in the following two drawings.

The regression equations obtained in this work as well as correlation factors in learning, assessment, checking, and the overall for the ANN network architecture regarding the moment magnitude have been shown in the fourth figure.

The target data of comparison for the moment magnitude from the publication [6]) with the output values (computed applying the neural network) for the network structure 2-5-5-1 show a very good agreement.

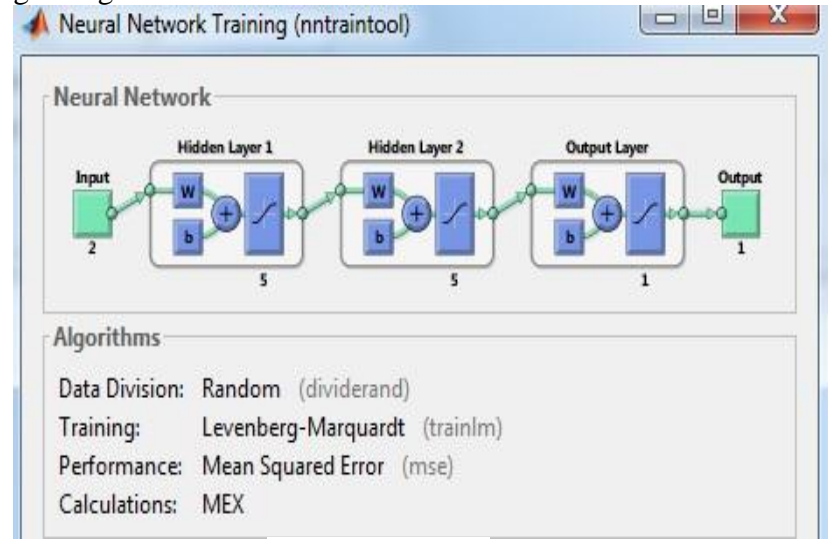

Fig. 1: The instance newly developed ANN network architecture with nodes and layers and some of the utilized algorithms.

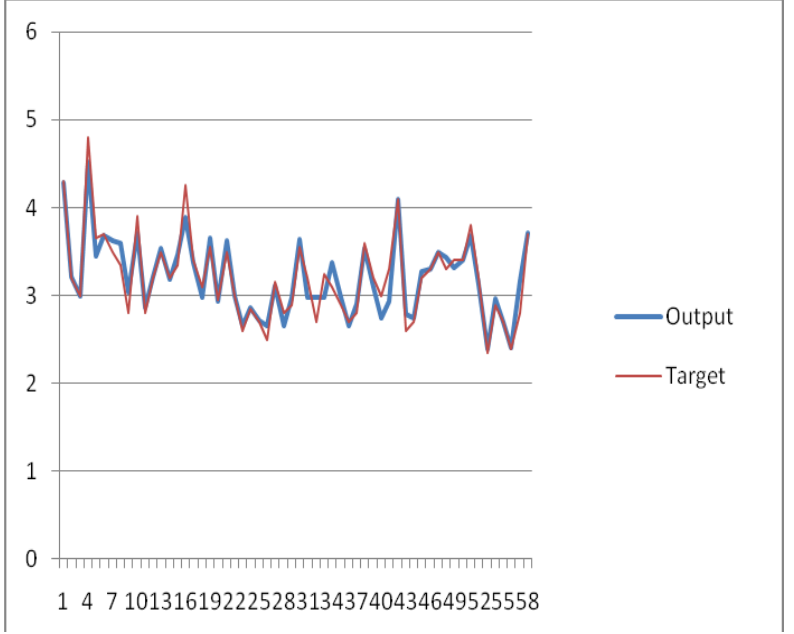

Fig. 2: The comparison diagram of the target positions for the moment magnitude values from [6] with the outputs (count applying the ANN architecture on Fig. 1).

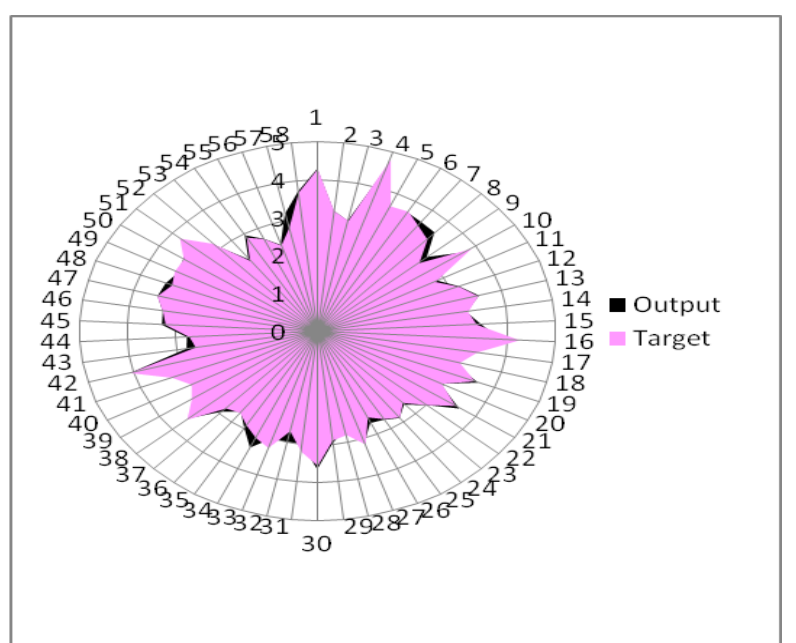

Fig. 3: The comparison radar plot of the target data for the moment magnitude values from [6] using the result parameters (count applying the ANN network architecture on Fig. 1).

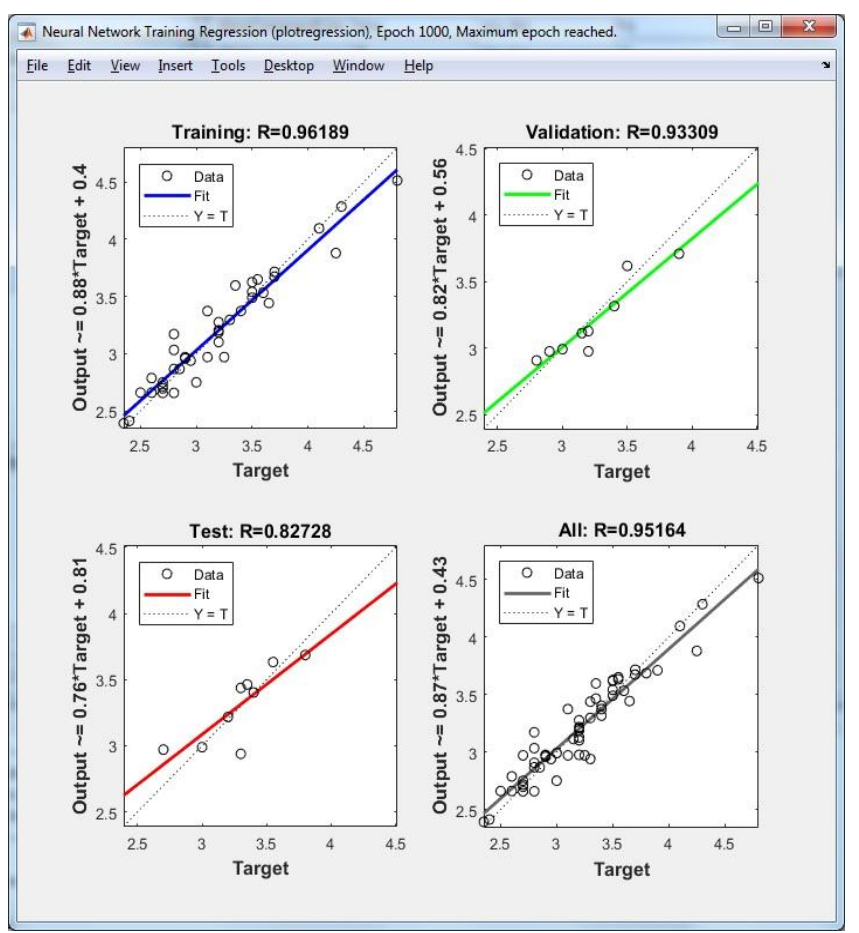

Fig. 4: Equations of the outputs, target as well as correlation factors in learning, assessment, checking, and the overall for the ANN network architecture on Fig. 1 for the moment magnitude values. 


\section{Conclusion}

Knowing the parameters of seismic impacts will provide the erection of structures, the minimization of expenditures for their seismic stability.

The use of these results in construction for the designed buildings and facilities and in the work of city technical services will lead to additional protection from potential seismic hazard, as well as to eliminate the negative impact on the existence of residents and the economy of the region as a whole.

\section{References}

[1] Aptikaev FF, Strong soil movements under earthquakes: seismic impacts, DrSc (Physics and Mathematics), Moscow, (2001).

[2] Sychev YV, "Risks of the man-made disasters of modern times", Internet Zhurnal Tekhnologii Tekhnosfernoy Bezopasnosti, Vol.41, (2012), http://ipb.mos.ru/ttb.

[3] Smirnov VI, "Seismic isolation - the modern seismic protection of buildings in Russia", Seismicheskoye stroitelstvo. Bezopasnost sooruzheniy, No. 4, (2013), pp.41- 52.

[4] Garrison WG, Large property damage losses in the hydrocarbonchemical industries. A thirty-year review, New York, (1998).

[5] Pustovitenko BG, Eredzhepov EE,'The energy spectra of forecas seismic effects for responsible construction projects in Yalta", $V i$ anik Odeskoi Derzhavnoy Akademii Budivnitstva ta Architekturi, No. 64, (2016), pp.227-233.

[6] Pustovitenko BG, Merger EA, AA Pustovitenko AA, "Dynamic parameters of the earthquake foci of Crimea according to digital seismic stations", Geofizicheskiy Zhurnal, Vol. 35, No. 5, (2013), pp.172-186.

[7] Haritonova L, "On the of neural modeling of some dynamic parameters of earthquakes and fare safety in high-rise construction", E3S Web of Conferences, Vol. 33, (2018), 02072, doi.org/10.1051/e3sconf/20183302072.

[8] Haritonova LP, "On the issue of neural network modeling to assess the energy consumption of large arrays of consumers (buildings)", International Research Journal, Vol.8, No.3 (50), (2016), pp.155158, DOI: 10.18454/IRJ.2016.50.176.

[9] Haritonova LP, "On the modeling of artificial neural networks in matlab to evaluate use of energy by a large array of buildings", International Scientific and Practical Conf. World science, Vol.8, No.12, (2016), pp.47-55

[10] Haritonova L, "On Neural Modeling of Heat Exchange in Heat Exchangers (Recuperators) with the Systems of Plane-Parallel Impingement Jets for Machine Building and Metallurgical Productions", Procedia Engineering, Vol. 206, (2017), pp.1002-1008, DOI information: 10.1016/j.proeng.2017.10.585

[11] Haritonova L, "On the mathematic simulation of the energy efficiency for heat exchangers with the systems of impingemen planeparallel jets. MATEC Web Conf., Vol.106, (2017), 06006 , doi.org/10.1051/matecconf/201710606006

[12] Haritonova L, "The Neural Modeling for the Assessment of Hazard ous Hydro Meteorological Phenomena Including Case of the Provid ing a Sustainable Work (Reliability) on Transport”, Ad vances in In telligent Systems and Computing, Springer, Cham., Vol. 692, (2018), pp.700-709, doi.org/10.1007/978-3-319-70987$1 \_74$. 